\title{
ENERGY MANAGEMENT OF COMPRESSED AIR SYSTEMS. ASSESSING THE PRODUCTION AND USE OF COMPRESSED AIR IN INDUSTRY
}

Sagastume, Alexis; Cabello-Eras, J. J; Sousa, Vladimir; Cabello Ulloa, Mario Javier

\begin{abstract}
The use of compressed air in industry is an important and yet overlooked energy carrier. Although there are different energy-saving measures discussed in the specialized literature, there is little discussion on the energy performance of the production and use of compressed air. This study developed a new approach to assess the energy performance of compressed air systems based on a six-step local energy benchmarking methodology. The methodology includes an energy management procedure to monitor and control the electricity consumption and sustain the energy performance of compressed air systems in time. The procedure monitors the production and use of compressed at plant and at manufacturing section levels based on the real-time monitoring of relevant variables to calculate energy performance indicators, energy baselines, and CUSUM charts. Monitoring the consumption of compressed air at the section level in a case study reduced the demand between 11 and $47 \%$. While electricity consumption to produce compressed air at the plant level reduced by an estimated $23 \%$. This approach permits the rapid detection of inefficiencies in the production and demand sides of the compressed air system, highlighting inefficiencies that are frequently hidden in the total electricity consumption of manufacturing plants. (C) 2020 Elsevier Ltd
\end{abstract}

\section{Keywords}

Compressed air, Compressors, Energy efficiency, Energy management 